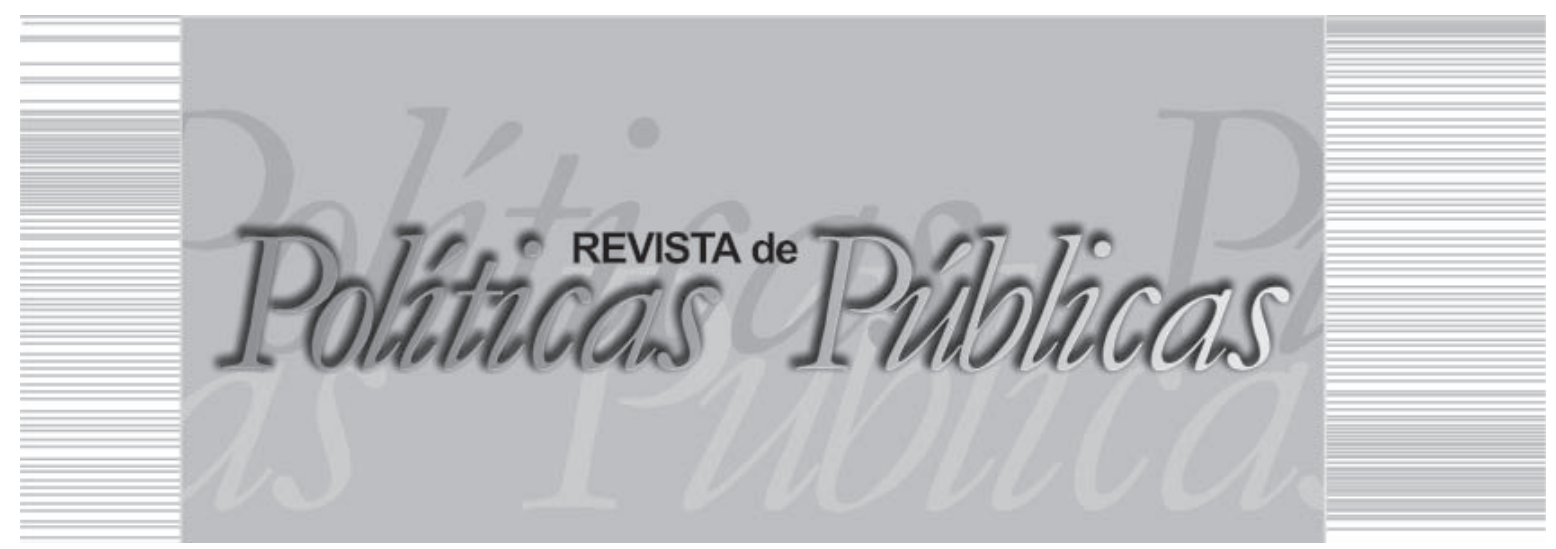

\title{
MERCANTILIZAÇÃO DA PREVIDÊNCIA SOCIAL E A CRIAÇÃO DO REGIME COMPLEMENTAR DOS SERVIDORES PÚBLICOS FEDERAIS
}

\author{
Ana Paula de Souza Oliveira ${ }^{1}$ \\ Universidade Federal do Amazonas (UFAM) \\ Ingrid Câmara Areque ${ }^{2}$ \\ Universidade Federal do Amazonas (UFAM) \\ Laiana Roberta Ferreira Barroso ${ }^{3}$ \\ Universidade Federal do Amazonas (UFAM) \\ Yoshiko Sassaki ${ }^{4}$ \\ Universidade Federal do Amazonas (UFAM)
}

\section{Resumo}

Este artigo analisa o processo de mercantilização do sistema público previdenciário brasileiro a partir das contrarreformas iniciadas na década de 90 , em especial as mudanças ocorridas no regime próprio de previdência social dos servidores públicos, com ênfase para a criação do Regime de Previdência

\footnotetext{
Assistente Social. Doutoranda em Sociedade e Cultura da Amazônia na Universidade Federal do Amazonas (UFAM). Assistente Social da UFAM | E-mail: hanaoliveira@ ufam.edu.br

2 Assistente Social. Mestre em Serviço Social pela Universidade Federal do Amazonas (UFAM). Assistente Social da UFAM | E-mail: ingrid.areque@bol.com.br

3 Graduanda em Direito. Assistente em Administração na Universidade Federal do Amazonas (UFAM) | E-mail: laiana.roberta@hotmail.com

4 Assistente Social. Doutora em Serviço Social. Professora Associada da Universidade Federal do Amazonas (UFAM). E-mail: sassakiyo@uol.com.br | Universidade Federal do Amazonas - UFAM | Departamento de Saúde e Qualidade de Vida - Av. Rodrigo Otávio Jordão Ramos, 6.200, Coroado I | CEP: 69080-900
} 
Complementar, regime este que reafirma a mudança do papel do Estado como regulador e provedor das políticas públicas e sociais, transferindo gradativamente essa responsabilidade para a iniciativa privada à custa da destituição dos direitos que foram arduamente conquistados.

Palavras-chave: contrarreformas, mercantilização, previdência complementar, servidores públicos federais.

\title{
COMMERCIALIZATION OF SOCIAL SECURITY AND THE CREATION OF THE SUPPLEMENTARY REGIME OF FEDERAL PUBLIC WORKERS
}

\begin{abstract}
This article analyzes the process of commodification of the Brazilian social security public system from counter-measures that started in the 90 s, especially the changes in own social security scheme for civil servants, with emphasis on the creation of the Supplementary Pension Regime, this regime reaffirms the change of the state's role as regulator and provider of public and social policies gradually transferring this responsibility to the private sector at the expense of the removal of rights that have been hard-won.

Key words: Countermeasures, commodification, complementary pension, federal public workers.
\end{abstract}

\section{INTRODUÇÃO}

Com a Constituição Federal (CF) de 1988, obteve-se um marco significativo no âmbito da proteção social ao ser instituído o conceito de Seguridade Social balizado no tripé: previdência, saúde e assistência social. No aspecto normativo, houve o reconhecimento da universalidade dos direitos humanos e sociais, prerrogativas essenciais do exercício da cidadania ampliada.

A Seguridade Social representou um grande avanço, ao ser constituída como um conjunto integrado de ações, como dever do Estado e direito do cidadão; de natureza universal, pública, democrática e redistributiva, mas de fato só a saúde o é em princípio, mas não de fato.

E a previdência que é contributiva, objeto deste estudo, sofreu várias reformas sempre contra os trabalhadores de modo geral. E o que não dizer do trabalhador do serviço público? Houve um avanço em 1990 com a instituição do Regime Jurídico Único (RJU) criado pela Lei $\mathrm{n}^{\circ}$ 8.112, de 11 de dezembro de 1990, mas em 1998 houve 
MERCANTILIZAÇÃO DA PREVIDÊNCIA SOCIAL E A CRIACCÃO DO REGIME COMPLEMENTAR DOS SERVIDORES PÚBLICOS FEDERAIS

minirreformas e mudanças significativas nos anos 2003, 2012 e a mais recente em 2015.

Em um processo que ainda está em curso, dentre as mudanças destacam-se o fim da aposentadoria integral e a instituição da previdência complementar, de caráter facultativo e, que a partir de 2015 passa a vigorar a adesão compulsória, e não fica claro se isso vai prejudicar mais ainda o servidor público federal.

Desse modo, buscamos analisar essas questões que envolvem novos servidores sobre a sua previdência frente à incerteza de como realmente será a aposentadoria estatal e via previdência complementar em vigor a partir de 2012.

Para tanto, realizamos uma revisão bibliográfica e estudo dessas legislações buscando refletir sobre essa questão e apontar possíveis caminhos de enfrentamento dessa obrigatoriedade e redução de direitos do servidor público.

Em primeiro momento analisaremos a conjuntura da década de 1990 e a contrarreforma instituída nesse período; em seguida refletimos sobre as reformas instituídas ao servidor público federal e a redução dos direitos previdenciários e analisamos o regime complementar vigente e suas distorções da facultatividade.

\section{AS CONTRARREFORMAS DA PREVIDÊNCIA}

SOCIAL NO BRASIL: entre a inovação e o conservadorismo neoliberal

A integração do Brasil ao contexto mundial preconizado pelo ideário neoliberal, ocorreu mais intensamente a partir dos anos 1990 do século XX no governo de Fernando Collor de Mello com a adoção das recomendações do Consenso de Washington:

\footnotetext{
Da liberação do comércio à política de privatização do Programa Nacional de Desestatização, Lei no ${ }^{\circ} .031 / 90$ (privatizando todo o setor siderúrgico [...]). Esse governo executou um conjunto de medidas para conter a hiperinflação baseada na redução da circulação da moeda e do consumo a partir do confisco das cadernetas de poupança e das contas correntes, ampliando consideravelmente o empobrecimento da população brasileira. (LIMA, 2007, p. 89)
}

Apesar do curto período de tempo que esteve na presidência do Brasil (1990-1991), devido seu governo ser marcado por escândalos e corrupções que resultaram no seu impeachment, teve um pa- 
pel estratégico para disseminar a concepção de que o setor público era ineficiente e com isso exaltar a eficiência do setor privado, reforçando a ideia da necessidade de ser realizada a reforma do Estado nos moldes previstos pelo ideário neoliberal, reforçada pela conjuntura internacional com o esfacelamento da União Soviética e queda do muro de Berlim, etc.

A política de Collor rompeu com o velho padrão nacional-desenvolvimentista e criou uma nova estratégia de desenvolvimento pautada na estabilização da moeda: "[...] congelou preços, confiscou moeda da população, reduziu parte da riqueza financeira das classes médias e empresariais." (SALLUM JR., 2003, p. 42).

Após a destituição de Fernando Collor de Melo, Itamar Franco, seu vice, assumiu a presidência, manteve a mesma orientação, moderadamente liberal e internacionalizante de integração da economia doméstica ao sistema econômico mundial, que, por sua vez, foram aprofundadas no governo de Fernando Henrique Cardoso (FHC), quando este assumiu a presidência em 1995 (SALLUM JR., 2003).

Ao se reportar ao papel do Estado, FHC destacou uma suposta crise causada pelo excessivo financiamento nas atividades econômicas e sociais, indicando a necessidade de sua reconfiguração, que veio a se concretizar sob o viés do Plano Diretor da Reforma do Aparelho do Estado elaborado na gestão de Luiz Bresser Pereira no Ministério da Administração e Reforma do Estado (MARE).

Na nova forma de acumulação do capital preconizada pelo ideário neoliberal, segundo o autor acima, o Estado é visto como instância necessária e estratégica nas reformulações, especialmente, dos países menos desenvolvidos para realizar as adequações estruturais segundo a lógica do grande capital conduzido através das orientações e intervenções dos organismos internacionais (Banco Mundial [BM], Banco Internacional de Reconstrução e Desenvolvimento [BIRD], Banco Interamericano de Desenvolvimento [BID], Fundo Monetário Internacional [FMI], Organização Mundial do Comércio $[\mathrm{OMC}])$.

Segundo Marconsin e Santos (2013), tal discurso foi adotado e vinculado pela mídia para justificar as mudanças regressivas, pois os direitos sociais e trabalhistas em terras brasileiras sempre foram 


\section{MERCANTILIZACẼO DA PREVIDÊNCIA SOCIAL E A CRIACCÃO}

DO REGIME COMPLEMENTAR DOS SERVIDORES PÚBLICOS FEDERAIS

mínimos e regulados pelo mercado, para garantir a manutenção do capital e as condições de exploração da força de trabalho.

Nesse sentido, Harvey (1992) aponta que segundo a retórica neoliberal faz-se necessário minimizar o papel do Estado, sobretudo nos aspectos sociais e maximizá-lo em favor do capital mediante a abertura comercial, desregulamentação dos mercados, flexibilização das relações trabalhistas, privatização das empresas estatais e com a transferência das suas tradicionais responsabilidades para a iniciativa privada; com isso presencia-se o início de outro estágio de acumulação do capital definido como Acumulação Flexível que "[...] se apoia na flexibilidade dos processos de trabalho, dos mercados de trabalho, dos produtos e padrões de consumo [...]" (HARVEY, 1992, p. 141-142).

Essa retórica neoliberal se concretiza quando, como parte de sua estratégia de legitimação, subordina o Estado Nacional, sobretudo dos países em desenvolvimento, às ordens dos organismos internacionais.

Faleiros (2000) explicita que são eles os responsáveis pela difusão do ideário neoliberal ao exercerem forte influência nas políticas públicas desses países, condicionando a ajuda financeira prestada às modificações das políticas públicas, tornando os Estados Nacionais reféns nessa relação desigual. "Desta forma, não se pode desvincular a reforma da previdência do novo papel do Estado neste contexto de mudanças do capitalismo contemporâneo." (FALEIROS, 2000, p. 101).

Dito isto, infere que "[...] as reformas da previdência no Brasil, não são, pois, meros arranjos conjunturais para um equilíbrio de caixa, como apregoa o governo, mas um processo de refundação das relações de acumulação e das relações de classe." (FALEIROS, 2000, p. 102).

Reforma essa em que os direitos dos trabalhadores são constantemente reduzidos como dever do Estado, sendo privatizados e mercantilizados, que força o indivíduo e a sociedade a enfrentarem as dificuldades a partir das suas próprias capacidades. 


\section{AS MUDANÇAS NO REGIME PREVIDENCIÁRIO DO SERVIDOR PÚBLICO FEDERAL E A REDUÇÃO DOS DIREITOS PREVIDENCIÁRIOS}

O processo de reformulação da previdência social brasileira teve início em março de 1995 no governo de FHC que encaminhou ao Congresso Nacional a proposta de reforma da previdência através da Emenda Constitucional (EC) no 33, de 28 de março de 1995. $\mathrm{O}$ argumento do governo para justificar a reforma era o crescente desequilíbrio financeiro do sistema que o tornava deficitário, sendo imperioso o controle dos gastos públicos, caso contrário não se auto sustentaria.

É pertinente destacar, conforme Amaro e Meneguin (2003), que a proposta inicial previa a unificação dos regimes previdenciários dos servidores públicos, incluindo militares e dos trabalhadores da iniciativa privada, bem como a criação de dois sistemas gerais, sendo um básico e unificado com benefícios limitados de três salários mínimos, operado pelo regime de repartição, e outro complementar e obrigatório baseado na capitalização, voltado para aqueles com remuneração de até dez salários mínimos e, acima deste de valor voluntário.

Contudo, até a sua aprovação, que foi consubstanciada somente em 15 de dezembro de 1998, através da EC no 20 , ou seja, depois de três anos e dez meses de tramitação, o texto sofreu várias alterações em pontos que eram considerados fundamentais pelo Poder Executivo.

Dentre as principais mudanças promovidas por essa reforma ao Regime Próprio de Previdência Social do Servidor Público (RPPS) destacam-se: a "[...] substituição do tempo de serviço por tempo de contribuição; o aumento da idade mínima; o estabelecimento do teto máximo dos benefícios; a instituição do regime contributivo para os servidores públicos e a criação do fator previdenciário, como norma de transição." (MOTA, 2007, p. 138).

Amaro e Meneguin (2003, p. 7) pontuam outras mudanças que passaram a vigorar com a $E C \mathrm{n}^{\circ}$ 20/1998: a imposição de 10 anos de serviço público para habilitação a aposentadorias programáveis e de 05 anos no cargo ocupado; o fim da acumulação de aposentadorias, bem como impossibilidade de aumento de renda quando da passagem do servidor para a inatividade. 
MERCANTILIZAÇÃO DA PREVIDÊNCIA SOCIAL E A CRIAÇÃO DO REGIME COMPLEMENTAR DOS SERVIDORES PÚBLICOS FEDERAIS

Tais mudanças marcaram o processo inicial de flexibilização da legislação trabalhista e de redução de direitos, ao provocar a regressão das políticas universais, em detrimento de políticas seletivas e focalizadas, o que contraria os princípios constitucionais.

Além disso, excluiu a aposentadoria especial para professores universitários e a contagem de tempo fictício, que permitia a contagem em dobro do tempo de licença-prêmio não gozada, e também o aumento da remuneração na aposentadoria com a integração de gratificações, bem como estabeleceu, o regime privado, de caráter complementar e facultativo (PACHECO FILHO, WINCKLER, 2005).

Como podemos verificar, a primeira Reforma Previdenciária consubstanciada através da $\mathrm{EC} \mathrm{n}^{\circ}$ 20/1998 apresentou alguns pontos que merecem reflexão, dentre os quais podemos destacar a mudança introduzida referente ao tempo de serviço para o tempo de contribuição, muito bem destacada por Duarte (2003) em sua reflexão sobre alterações que a referida emenda acarretou para o Regime Geral de Previdência Social (RGPS), operado pelo Instituto Nacional do Seguro Social (INSS).

Continua essa autora que, ao desvincular o acesso à aposentadoria pelo tempo de trabalho existente e instituir a contribuição, reforçaram a lógica do seguro garantido pela capacidade contributiva de cada indivíduo. Com essa mudança no padrão de regulação social, o trabalho deixa de ser porta de entrada para o acesso à proteção social, como ocorreu historicamente.

Isso se agrava, sobretudo no âmbito do RGPS, pois tal mudança contribuiu para legitimação do trabalho informal, bem como para acentuar a dicotomia entre os dois regimes previdenciários (RGPS e RPPS) no que se refere ao processo de individualização, fragilizando dessa forma a dimensão coletiva na luta pela garantia dos direitos sociais.

Outro ponto que merece destaque se refere à instituição do fator idade, baseado na expectativa de vida, o que inclusive já se cogita no atual governo do Presidente interino Michel Temer, mediante outra reforma previdenciária de aumentar novamente a idade e também o tempo de contribuição.

Ocorre que tal medida de elevar a idade e também o tempo de contribuição não leva em consideração as especificidades do processo de envelhecimento, que em nosso país é marcado pelo não in- 
vestimento do Estado ao longo da vida dos brasileiros, desemprego estrutural e inserções precarizadas de trabalho.

Diante disso, os trabalhadores idosos das classes populares, que durante a vida ativa vivenciaram relações informais e precarizadas de trabalho e não amealharam recursos financeiros, hoje destituídos da sua força de trabalho e com saúde comprometida, muitos por não atender aos requisitos para concessão da aposentadoria, possivelmente ficarão abaixo do nível do Índice de Desenvolvimento Humano (IDH), preconizado pela Organização das Nações Unidas (ONU), ocupando a fila para possível acesso à Assistência Social.

Essa reforma foi responsável por instituir a previdência complementar para os servidores públicos, de caráter facultativo. Apesar de não ter concretizado todos os objetivos pretendidos, a EC n'20/1998 deixou o caminho traçado para que os governos posteriores pudessem finalizá-lo, se não igual, pelo menos o mais próximo possível dos moldes inicialmente pretendidos.

A continuidade do desmonte ocorreu com a aprovação da EC $\mathrm{n}^{\mathrm{o}} 41$, de 19 de dezembro de 2003, no mandato presidencial de Luiz Inácio Lula da Silva, que retirou dos servidores públicos o direito à aposentadoria integral por tempo de serviço.

Mota (2007, p. 139) afirma que "[...] ao substituir este direito pela opção de associar-se a um fundo de previdência complementar, o governo penalizou duplamente o servidor que deverá custear esta poupança compulsória com seus salários já defasados."

Segundo a autora, essa Emenda "[...] alterou o limite de idade, o teto das aposentadorias e pensões, as regras de paridade, o tempo de permanência no serviço público e instituiu a contribuição dos inativos." (MOTA, 2007, p. 139).

Além disso, a referida EC prevê o abono permanência ao servidor que opte por permanecer em atividade tendo completado as exigências para aposentadoria voluntária e que conte com, no mínimo, 25 anos de contribuição, se mulher, ou 30 anos de contribuição, se homem; institui a contribuição de inativos e pensionistas em onze por cento incidente sobre a parcela dos proventos de aposentadorias e pensões que supere $60 \%$ do limite máximo estabelecido para os benefícios do RGPS, bem como estabeleceu que o regime de previdência complementar fosse instituído por lei de iniciativa do respectivo Poder Executivo, por intermédio de entidades fechadas de 


\section{MERCANTILIZACẼO DA PREVIDÊNCIA SOCIAL E A CRIACÃO}

DO REGIME COMPLEMENTAR DOS SERVIDORES PÚBLICOS FEDERAIS

previdência complementar, de natureza pública, que oferecerão aos respectivos participantes planos de benefícios somente na modalidade de contribuição definida.

No ano de 2005, o governo Lula aprovou a $\mathrm{EC}$ n ${ }^{\circ} 47$, de 5 de julho de 2005, que é complementar da $E C n^{\circ} 41 / 2003$. A principal mudança introduzida foi a possibilidade dos servidores que ingressaram no serviço público até 15 de dezembro de 1998 e que tivessem mais de 35 anos de contribuição, se homem, e mais de 30 anos, se mulher, abaterem o tempo de contribuição excedente na idade mínima. Somada aos requisitos de cumprir 25 anos de efetivo exercício no serviço público, 15 anos de carreira e 05 anos no cargo em que se der a aposentadoria, fazendo jus à aposentadoria integral. (BRASIL, 2003).

Ainda no rol de contrarreformas realizadas no sistema previdenciário do servidor público, o governo da presidente Dilma Rousseff instituiu a EC n ${ }^{\circ} 70$, de 29 de março de 2012, que introduziu mudanças na aposentadoria por invalidez, que estabeleceu novas regras de concessão de pensão por morte, através da Lei no 13.135 , de 17 de junho de 2015, bem como regulamentou a criação do Regime de Previdência Complementar para os servidores públicos federais titulares de cargo efetivo, através da Lei $n^{\circ} 12.618$, de 30 de abril de 2012.

Para aprofundar ainda mais o quadro de perdas dos direitos garantidos constitucionalmente em um golpe contra os servidores públicos, em 04 de novembro de 2015 foi sancionada a Lei 13.183 que retirou a natureza facultativa da adesão aos planos de benefícios administrados pelas fundações de previdência complementar do Executivo, Legislativo e Judiciário.

Estabelece que todos os servidores públicos com remuneração superior ao limite máximo estabelecido para os benefícios do RGPS que ingressarem no serviço público a partir de 3 de janeiro de 2016, sejam automaticamente inscritos no fundo de pensão. A referida Lei estabelece o prazo de 90 dias para os servidores que desejarem cancelar sua adesão, para fins de restituição integral de suas contribuições.

O servidor público cuja remuneração é superior ao teto do RGPS é incentivado em nome da liberdade do mercado a buscar a rentabilidade dos planos privados para complementação da apo- 
sentadoria, em decorrência da destituição do direito à previdência integral.

Diante das incertezas que aguardam os futuros servidores públicos acerca dos seus direitos previdenciários, após 80 anos de transição dos fundos de provisão corporativos (Caixas de Aposentadorias e Pensões [CAPS] e Institutos de Aposentadorias e Pensões [IAPS]) para construção de um fundo público e universal, como a Seguridade Social, prevista na CF de 1988, nos deparamos com a reatualização dos velhos e corporativos, Fundos de Pensão. (MARQUES, 2003).

Nesse contexto, conforme assevera Faleiros (2000), as reformas da previdência são demarcadas por um processo contraditório, uma vez que os trabalhadores lutam por garantir seus direitos. De outro lado os grandes negócios e o capital financeiro, que são os que detêm o poder nessa relação desigual, promovem uma política de eliminação e redução de direitos, para sustentar com mais força as bases de uma produção complexa, sem salários estáveis, com fundos privados ao invés de fundos públicos, e com um Estado desregulamentado.

Boschetti e Moreira (2016) explicitam que, por trás do discurso oficial, a velha fórmula de defesa para crise econômica e política é a redução dos investimentos sociais, desoneração e renúncias tributárias para o empresariado e transferência dos custos para a classe trabalhadora.

Assim, na tentativa de despolitizar a discussão da Previdência Social ao qualificar o servidor público como privilegiado, enquanto somos sabedores, conforme ratificam as autoras Mota (2007) e Marques (2003), que suas aposentadorias não são responsáveis pelos desequilíbrios das contas públicas.

Marques (2003, p. 29) evidencia que ao "[...] comparar a renda da vida toda, isto é, do período da atividade e da aposentadoria, entre um servidor e um assalariado do mercado formal do setor privado, verificaremos que elas tendem a ser iguais, indicando que os servidores não constituem segmento privilegiado."

Ou seja, "[...] vende-se a ideia de que o trabalho perdeu a sua capacidade de integrar os indivíduos na sociedade.", buscando legitimar a dicotomia entre público e privado na tentativa de criar as condições favoráveis para o processo de mercantilização dos servi- 
MERCANTILIZACỸ̃O DA PREVIDÊNCIA SOCIAL E A CRIACYÃO DO REGIME COMPLEMENTAR DOS SERVIDORES PÚBLICOS FEDERAIS

ços sociais e de individualização das relações sociais. (DUARTE, 2003, p. 136).

Diante disso, se desfaz a ideia de dever do Estado e direito do cidadão e legitima a figura do indivíduo consumidor e das instituições do mercado; no caso específico da previdência, abre-se o caminho para a expansão dos planos privados e, no caso do servidor público para fundos de pensão e "[...] perde-se a condição de um sistema de proteção à base de uma transferência intergeracional e funcional da renda." (MOTA, 2007, p. 148).

\section{REGIME COMPLEMENTAR E A ADESÃO COMPULSÓRIA DOS SERVIDORES PÚBLICOS FEDERAIS}

Com a retórica de diminuir os débitos gerados com a manutenção de um Sistema de Previdência Social em especial, com os Regimes Próprios de Previdência Social, foi instituída pela União a Lei ${ }^{\circ} 12.618 / 2012$, que criou o regime de previdência complementar para os servidores públicos federais titulares de cargos efetivos.

O Sistema de Previdência Complementar, instituído em nosso país, é formado por dois grandes grupos de entidades: Entidades Abertas de Previdência Privada (EAPP) e as Entidades Fechadas de Previdência Privada (EFPP).

De acordo com Mota (2007, p. 145), "[...] as EAPP são usualmente, empresas independentes e abertas ao público em geral, podendo ter fins lucrativos (ou não), as EFPP são organizadas como sociedades civis, sem fins lucrativos, com clientela específica."

A ampliação dos sistemas privados para uma faixa antes coberta pelo sistema, bem como a busca dos serviços complementares, surgem na medida em que o papel do Estado torna-se reduzido, pois a nova medida desvincula o acesso dos trabalhadores a determinados benefícios que estão condicionados à inserção formal no mercado de trabalho e à capacidade individual de contribuição.

Não obstante a extinção da paridade e integralidade remuneratória, a partir da $\mathrm{EC} \mathrm{n}^{\circ} 41 / 2003$, os novos servidores e seus beneficiários terão seus ganhos de aposentadorias e pensões adstritos ao teto do RGPS, após a criação da Lei nº 12.618/2012. 
Trata-se de um verdadeiro retrocesso dos direitos conquistados pelos servidores públicos federais, visto ser a Previdência um direito social elencado no rol do artigo $7^{\circ}$ do Texto Constitucional.

O rebaixamento do teto dos benefícios da previdência pública contribuiu para a corrida dos trabalhadores aos planos de previdência privada, na busca de complementarem suas aposentadorias. São "[...] conceituados como sistema complementares pelo fato de proverem complementação de aposentadorias, pecúlios, benefícios e pensões da Previdência oficial." (MOTA, 2007, p. 148).

Diferentemente dos direitos individuais (voto, liberdade de opção sexual, religiosa), os direitos sociais, ditos de segunda ordem, exigem não só uma conduta liberal do Estado, como também exigem uma prestação positiva dele.

No conceito de Silva (2016), são prestações positivas proporcionadas pelo Estado direta ou indiretamente, enunciadas em normas constitucionais, que possibilitam melhores condições de vida aos mais fracos, direitos que tendem a realizar a igualização de situações sociais desiguais. Não é isso, porém, o que representa a Lei $\mathrm{n}^{\mathrm{o}} 12.618 / 2012$.

Outrossim, a previdência complementar encontra previsão Constitucional no art. 202, com redação dada pela EC nº 20/1998:

\begin{abstract}
Art. 202. O regime de previdência privada, de caráter complementar e organizado de forma autônoma em relação ao regime geral de previdência social, será facultativo, baseado na constituição de reservas que garantam o benefício contratado, e regulado por lei complementar.

$\S 4^{\circ}$ Lei complementar disciplinará a relação entre a União, Estados, Distrito Federal ou Municípios, inclusive suas autarquias, fundações, sociedades de economia mista e empresas controladas direta ou indiretamente, enquanto patrocinadoras de entidades fechadas de previdência privada, e suas respectivas entidades fechadas de previdência privada. (BRASIL, 1998).
\end{abstract}

Da leitura do texto constitucional depreendem-se as seguintes características: caráter complementar, autonomia em relação ao RGPS; facultatividade, constituição de reservas e disciplinada por Lei Complementar.

Contudo, a conversão da Medida Provisória (MP) $\mathrm{n}^{0}$ 676, de 17 de junho de 2015 na Lei $\mathrm{n}^{\circ}$ 13.183/2015 que, dentre outras 


\section{MERCANTILIZAÇÃO DA PREVIDÊNCIA SOCIAL E A CRIAÇÃO DO REGIME COMPLEMENTAR DOS SERVIDORES PÚBLICOS FEDERAIS}

providências, altera a Lei $\mathrm{n}^{\circ}$ 12.618/2012 que instituiu o regime de previdência complementar para os servidores públicos federais titulares de cargos efetivos, subverte estas características, notadamente, o conceito de facultatividade.

O traço marcante da previdência complementar é o seu caráter facultativo, ou seja, a adesão é espontânea, depende de ato de disposição da vontade. Diante disso, entende-se que mesmo a despeito do controle estatal no que concerne aos planos ofertados, a relação jurídica é de cunho contratual. (AMADO, 2014).

No entanto, a Lei $\mathrm{n}^{\circ} 13.183 / 2015$ retira a natureza facultativa da adesão aos planos de benefícios administrativos pelas fundações de previdência complementar do Executivo, Legislativo e Judiciário, porém estabelece prazo de 90 dias para os servidores que desejarem solicitar o cancelamento. (BRASIL, 2015).

A Lei $n^{\circ} 13.183 / 2015$ estabelece que os servidores com remuneração superior ao limite máximo estabelecido para os benefícios do RGPS que ingressarem no serviço público a partir do início da vigência do regime de previdência complementar, ou seja, a partir de 3 de janeiro de 2016, serão automaticamente inscritos no respectivo plano de previdência complementar desde a data de entrada em exercício. (BRASIL, 2015).

Ademais, estabelece prazo de 90 (noventa) dias entre a inscrição e o pedido de cancelamento como marco temporal para reconhecimento do direito à restituição integral das contribuições. Portanto, infere-se que o servidor que requeira o cancelamento a partir do $91^{\circ}$ dia não terá mais direito ao ressarcimento integral daquilo que sequer teve o direito de escolher pagar. Há uma clara afronta à isonomia.

A supracitada Lei padece de vícios de inconstitucionalidade formais e materiais. A primeira, por sua vez, se caracteriza pela inobservância às regras de processo legislativo e, a segunda, por contrariar normas ou princípios constitucionais.

A MP n ${ }^{0} 676 / 205$ que resultou na Lei ${ }^{\circ} 13.183 / 2015$ traz no texto original não apenas a criação da regra $85 / 95$ progressiva no âmbito do Regime Geral, como também aprovou a $E C \mathrm{n}^{0} 34$, que trata sobre a adesão obrigatória à Fundação de Previdência Complementar do Servidor Público Federal (FUNPRESP) - Entidade Fechada de Previdência Complementar dos servidores públicos federais 
- ou seja, matéria afeta ao Regime Jurídico Estatutário Federal de competência privativa da Presidência da República.

Trata-se da chamada emenda jabuti, técnica legislativa que visa incluir emendas em projetos de conversão de Medidas Provisórias com assuntos estranhos ao texto originalmente publicado. Caracteriza-se como uma prática que visa ao contrabando legislativo e, por isso, claramente inconstitucional. Nessa linha, ratificou o Supremo Tribunal Federal (STF) sua jurisprudência no julgamento da Ação Direta de Inconstitucionalidade $n^{0} 5127$ :

Decisão: O Tribunal, por maioria, julgou improcedente o pedido formulado na ação direta com cientificação do Poder Legislativo de que o Supremo Tribunal Federal afirmou, com efeitos ex nunc, não ser compatível com a Constituição a apresentação de emendas sem relação de pertinência temática com medida provisória submetida a sua apreciação, vencidos os Ministros Rosa Weber (Relatora), Marco Aurélio e Ricardo Lewandowski, que julgavam procedente o pedido, e, em maior extensão, o Ministro Dias Toffoli, que o julgava improcedente. Redigirá o acórdão o Ministro Edson Fachin. Presidiu o julgamento o Ministro Ricardo Lewandowski. Plenário, 15.10.2015. (BRASIL, 2015).

A falta de pertinência temática também se evidencia pela característica de autonomia do RPPS e o RGPS. O regime próprio dos servidores públicos efetivos da União, Estados e Municípios estabelece a obrigatoriedade de contribuição aos pensionistas e aos aposentados. Ademais, que as regras do RGPS ocorrem de forma subsidiária, conforme art. 40, parágrafo 12 do Texto Constitucional.

\subsection{A distorção do princípio da facultatividade}

A Lei $\mathrm{n}^{0} 12.618 / 2012$, com redação dada pela Lei $\mathrm{n}^{0}$ $13.183 / 2015$, contém as seguintes disposições:

$\S 2^{\circ}$ Os servidores e os membros referidos no caput deste artigo com remuneração superior ao limite máximo estabelecido para os benefícios do Regime Geral de Previdência Social, que venham a ingressar no serviço público a partir do início da vigência do regime de previdência complementar de que trata esta Lei, serão automaticamente inscritos no respectivo plano de previdência complementar desde a data de entrada em exercício.

$\S 3^{\circ}$ Fica assegurado ao participante o direito de requerer, a qualquer tempo, o cancelamento de sua inscrição, nos termos do regulamento do plano de benefícios. (BRASIL, 2015). 
MERCANTILIZAÇÃO DA PREVIDÊNCIA SOCIAL E A CRIAÇÃO DO REGIME COMPLEMENTAR DOS SERVIDORES PÚBLICOS FEDERAIS

A partir da leitura dos dispositivos legais, depreende-se que a adesão à FUNPRESP decorre de simples investidura em cargo público efetivo de servidor que receba remuneração acima do teto do RGPS, aliada ao fato da possibilidade de devolução dos valores somente depois de decorrido o prazo de 90 dias. Tal regra contraria frontalmente o Art. 40, § 15 da Constituição Federal.

Santos (2005, p. 67) define facultatividade:

[...] a previdência privada é regime facultativo porque o participante não é obrigado a aderir ou filiar-se a ele. Em consequência, suas receitas são arrecadadas sob a forma de contribuições voluntárias das pessoas físicas e/ou das pessoas jurídicas instituidoras ou patrocinadoras, enquanto que as receitas do regime da previdência social são arrecadadas sob a forma de tributos (contribuição previdenciária), ou seja, trata-se de obrigações compulsórias oriundas e regidas por lei, cuja arrecadação é efetuada por atividade administrativa plenamente vinculada, nos termos do Art. $3^{\circ}$ do Código Tributário Nacional - CTN.

A Lei Complementar $n^{\circ} 109$, de 29 de maio de 2001, que traz regras sobre a previdência complementar, impôs a todas as entidades de previdência complementar a obrigação de fornecimento de uma série de documentos, notadamente o certificado, regulamento do plano e cartilha, quando da inscrição do participante no plano de benefícios e não em momento posterior, in verbis:

Art. 10. Deverão constar dos regulamentos dos planos de benefícios, das propostas de inscrição e dos certificados de participantes condições mínimas a serem fixadas pelo órgão regulador e fiscalizador.

$\S 1^{\circ} \mathrm{A}$ todo pretendente será disponibilizado e a todo participante entregue, quando de sua inscrição no plano de benefícios:

I - certificado onde estarão indicados os requisitos que regulam a admissão e a manutenção da qualidade de participante, bem como os requisitos de elegibilidade e forma de cálculo dos benefícios;

II - cópia do regulamento atualizado do plano de benefícios e material explicativo que descreva, em linguagem simples e precisa, as características do plano;

III - cópia do contrato, no caso de plano coletivo de que trata o inciso II do art. 26 desta Lei Complementar; e

IV - outros documentos que vierem a ser especificados pelo órgão regulador e fiscalizador. 
$\S 2^{\circ} \mathrm{Na}$ divulgação dos planos de benefícios, não poderão ser incluídas informações diferentes das que figurem nos documentos referidos neste artigo. (BRASIL, 2001).

Com efeito, qualquer relativização ou mitigação dessas obrigações somente poderia ser veiculada por Lei Complementar, uma vez que embora não haja hierarquia entre lei complementar e lei ordinária, a lei complementar exige um quórum de maioria absoluta.

Portanto, matérias reguladas por leis complementares só podem ser revogadas por esta espécie legislativa, sob pena de inconstitucionalidade formal por não observância de pressupostos do ato. Ademais, posterga o conhecimento dos direitos e obrigações constantes do regulamento do plano a momento posterior à inscrição do participante. Dessa forma, contraria o conceito de boa-fé, o qual deve permear todas as relações jurídicas.

Um exemplo disso é que nos planos da Fundação de Previdência Complementar do Servidor Público Federal do Poder Executivo (FUNPRESP-Exe), Fundação de Previdência Complementar do Servidor Público Federal do Poder Legislativo (FUNPRESP-Leg), os servidores poderão escolher apenas três alíquotas: 7,5\%,8\% ou $8,5 \%$. No caso do patrocinador (ente público), a sua alíquota será a mesma do participante, mas não excedente a 8,5\%. Na hipótese da inscrição automática, indaga-se qual alíquota será aplicada pela administração pública para efetuar os descontos na remuneração do participante?

Ademais, Amado (2014) alerta que a renda dos benefícios a serem concedidos não são previamente definidos, pois irá decorrer do rendimento líquido da aplicação, o que traz insegurança previdenciária aos servidores que recebem muito acima do teto do salário de contribuição do RGPS e terão as suas aposentadorias pelo RPPS limitadas a esse valor, sem saber previamente qual será o quantum do benefício a ser pago pelo regime complementar.

A despeito de haver devolução dos valores requeridos num prazo de até 90 dias da data de inscrição, tal argumento não se mostra capaz de mitigar a ofensa ao princípio da facultatividade, presente no texto constitucional. Há uma inversão deliberada de pressupostos lógicos: a filiação é obrigatória e o cancelamento é facultativo.

Diante desse quadro de inúmeras violações à Constituição, acreditava-se que a solução para RPPS era complementariedade do 
MERCANTILIZAÇÃO DA PREVIDÊNCIA SOCIAL E A CRIAÇÃO DO REGIME COMPLEMENTAR DOS SERVIDORES PÚBLICOS FEDERAIS

regime, mas não somente isso, como também a adesão compulsória. Porém, o que se nota é a redução de direitos e o aumento das divergências entre antigos e novos servidores, no que concerne ao direito de aposentadoria integral dos primeiros e proporcional via regime complementar dos segundos.

\section{CONCLUSÃO}

Do exposto, verifica-se que o discurso governamental da necessidade de garantir o equilíbrio atuarial e financeiro do sistema previdenciário, utilizado para justificar o processo de contrarreformas efetivadas no setor, na verdade encobre o novo papel do Estado no atual modelo de acumulação do capital preconizado pelo ideário neoliberal e sob hegemonia dos organismos financeiros internacionais.

Ou seja, reduzir seu espaço de atuação como provedor das políticas sociais e de garantia dos direitos e submetê-las à lei do mercado caminhando deste modo, em direção oposta ao modelo proposto no texto original da CF de 1988.

O discurso da inviabilidade do sistema de seguridade social público e universal criou um divisor de águas entre os trabalhadores regidos pela Consolidação das Leis do Trabalho (CLT) e os do RJU, ao despolitizar a discussão da Seguridade Social e, especialmente, a da Previdência Social.

As reformas efetivadas no sistema previdenciário brasileiro se concretizaram através da redução do universo de cobertura dos direitos previdenciários e mediante a privatização do sistema, apontando para um processo de desconstrução da concepção de seguridade instituída na CF de 1988, baseada nos princípios de equidade e justiça social " [...] onde o Estado era o principal responsável pelo financiamento e pela organização do sistema, buscando a redistribuição de renda e a correção das desigualdades imposta pelo mercado." (TEIXEIRA, 2001, p. 51).

O processo de desconstrução que caminha em direção à legitimação do modelo de seguro social, compreendido "[...] como um mecanismo de proteção social em que o direito social se estabelece com base em um contrato, onde os benefícios são proporcionais à contribuição social que é efetivada [...]" (FREURY, 1991 apud TEIXEIRA, 2001, p. 51). 
Exemplo claro desse modelo de proteção ocorre com a criação do Regime de Previdência Complementar para os servidores públicos federais, que diferente do regime da previdência social, sua manutenção depende dos investimentos dos trabalhadores, seguindo, portanto, a lógica do mercado.

Sob os argumentos da redução dos gastos do Estado, da justiça entre remuneração de ativos e inativos e da liberdade individual do trabalhador em escolher os meios de obter uma melhor aposentadoria, está a estratégia de enfrentamento da crise econômica e a inserção do Brasil na dinâmica da mundialização financeira.

Não se trata de simplesmente negar a legitimidade dos planos privados de complementação de aposentadoria, mas de trazer a discussão às incertezas vivenciadas por esse processo ainda não acabado. Pois poderemos estimar o custo da complementação para o servidor público federal, mas não temos como estimar o valor que retornará ao mesmo e, se de fato, chegará a complementar a sua aposentadoria, pois as regras não estão claras e estão condicionadas à financeirização da economia.

Por fim, as reformas processadas no sistema previdenciário brasileiro, e especialmente no tocante ao servidor público, contribuíram para fragilizar a luta coletiva por políticas públicas de proteção social. E fragmentou a proteção coletiva dos trabalhadores em ações pontuais, focais e na cobertura mínima para aqueles destituídos da força de trabalho e dos meios de produção.

De modo que os novos servidores, sob esse regime complementar, ao se aposentarem no futuro incerto, receberão o mesmo valor dos aposentados pelo regime integral? Fica em aberto essa resposta.

\section{REFERÊNCIAS}

AMADO, F. Curso de Direito e Processo Previdenciário. 5 ed, Salvador: Juspodivm, 2014.

AMARO, M. N. \& MENEGUIN, F. B. Previdência Social no Brasil: o que foi feito, o que falta fazer. In: Revista de Informação Legislativa, $\mathrm{n}^{\circ}$ 157. Brasília: Senado Federal, jan/mar- 2003.

BOSCHETTI, I.; MOREIRA, M. Previdência social sob ataque explícito. Informativo Anual do Conjunto CFESS - CRESS, Brasília, DF, 2. ed., maio 2016. 


\section{MERCANTILIZACCÃO DA PREVIDÊNCIA SOCIAL E A CRIACC̃̃O DO REGIME COMPLEMENTAR DOS SERVIDORES PÚBLICOS FEDERAIS}

BRASIL. Constituição da República Federativa do Brasil. Constituição de 1988. Brasília, DF, 1988.

. Presidência da República. Emenda Constitucional n ${ }^{\circ} 20$, de 15 de dezembro de 1998. Modifica o sistema de previdência social, estabelece normas de transição e dá outras providências. Diário Oficial da União, Brasília, DF, 1998.

. Emenda Constitucional no 41, de 19 de dezembro de 2003. Modifica os arts. 37, 40, 42, 48, 96, 149 e 201 da Constituição Federal, revoga o inciso IX do $\S 3$ do art. 142 da Constituição Federal e dispositivos da Emenda Constitucional $\mathrm{n}^{\circ}$ 20, de 15 de dezembro de 1998, e dá outras providências. Diário Oficial da União, Brasília, DF, 2003.

Lei Complementar $n^{\circ} 109$, de 29 de maio de 2001. Dispõe sobre o Regime de Previdência Complementar e dá outras providências. Diário Oficial da União, Brasília, DF, 2001.

. Lei ${ }^{\circ} 13.183$, de 04 de novembro de 2015. Altera as Leis $n^{\circ} \mathrm{s} 8.212$, de 24 de julho de 1991, e 8.213, de 24 de julho de 1991, a Lei $\mathrm{n}^{\circ} 10.779$, de 25 de novembro de 2003, a Lei $\mathrm{n}^{\circ} 12.618$, de 30 de abril de 2012, a Lei n ${ }^{\circ} 10.820$, de 17 de dezembro de 2003, a Lei $n^{0} 7.998$, de 11 de janeiro de 1990; e dá outras providências. Diário Oficial da União, Brasília, DF, 2015.

Supremo Tribunal Federal. Medida provisória: emenda parlamentar e "contrabando legislativo" - 3. Informativo STF, Brasília, DF, n. 803, 2015. Disponível em:<http://www.stf.jus.br/ arquivo/informativo/documento/informativo803.htm>. Acesso em: 6 jul. 2016.

DUARTE, A. O processo de reforma da previdência social pública brasileira: um novo padrão de regulação social do Estado? Revista Serviço Social e Sociedade, São Paulo, n. 73, maio 2003.

FALEIROS, V. de P. A questão da reforma da previdência social no Brasil. Revista Ser Social, Brasília, DF, n. 7, 2000.

HARVEY, D. Condição Pós-Moderna: uma pesquisa sobre as origens da mudança cultural. São Paulo: Loyola, 1992.

LIMA, K. Contra-Reforma na educação superior: de FHC a Lula. São Paulo: Xamã, 2007.

MARCONSIN, C.; SANTOS, C. Direitos trabalhistas e previdência social: a experiência brasileira de flexibilização e desmonte. In:

MARCONSIN, C.; MARQUES, M. C. S. (Orgs.). Trabalho e direito: 
conquistas e retrocessos em debate. 2 ed. Rio de Janeiro: Lumen Juris, 2013.

MARQUES, R. M. et al. A previdência social no Brasil. 1 ed. São Paulo: Fundação Perseu Abramo, 2003.

MOTA, A. E. Crônicas de uma morte anunciada: as reformas da Previdência Social brasileira nos anos 1990 e 2000. In: BRAGA, L.; CABRAL, M. do S. R. (Orgs.). O serviço Social na Previdência: trajetória, projetos profissionais e saberes. São Paulo: Cortez, 2007.

PACHECO FILHO, C.; WINCKLER, C. R. Reforma da Previdência: o ajuste no Serviço Público. Indicadores Econômicos, Porto Alegre, v. 32, n. 4, p.221-248, mar. 2005.

SALLUM JR, B. Metamorfoses do estado brasileiro no final do século XX. Revista Brasileira de Ciências Sociais, São Paulo, v. 18, n. 52, p. 35-54, jun. 2003.

SANTOS, J. J. dos. Previdência Privada. Rio de Janeiro: Editora e Livraria Jurídica, 2005.

SILVA, J. A. da. Curso de Direito Constitucional Positivo. 39. ed. São Paulo: Malheiros, 2016.

TEIXEIRA, A. M. de P. Reforma e contra-reforma da Previdência Social no Brasil de hoje. Revista Katálysis, Florianópolis, n. 5, p. 4959, jul./dez. 2001. 